\title{
Correction to: An environmental DNA tool for monitoring the status of the Critically Endangered Smalltooth Sawfish, Pristis pectinata, in the western Atlantic
}

\author{
Ryan N. Lehman ${ }^{1} \cdot$ Gregg R. Poulakis $^{2} \cdot$ Rachel M. Scharer $^{2} \cdot$ Katherine E. Schweiss ${ }^{1} \cdot$ Jill M. Hendon ${ }^{3}$. \\ Nicole M. Phillips ${ }^{1} \mathbb{0}$
}

Published online: 10 November 2021

(c) Springer Nature B.V. 2021

\section{Correction to: \\ Conservation Genetics Resources (2020) 12:621-629 \\ https://doi.org/10.1007/s12686-020-01149-5}

After publication of the original article (Lehman et al. 2020), the authors noted the following errors in the main text:

1. The reverse primer sequence on Page: 3, Column: 1 , Line: 49 was not represented in the reverse complementary format.

The correct reverse primer sequence is: (PpecR: 5'-GAA GGAGAGCTGAAGCTGTAGC-3').

2. The probe sequence on Page: 3 , Column: 2 , Lines: $2-3$ was incorrect.

The correct probe sequence is: (PpecIBQF: 5'-CATCCA CGAGCAGTAGAAGCCA-3').

Publisher's Note Springer Nature remains neutral with regard to jurisdictional claims in published maps and institutional affiliations.

The original article can be found online at https://doi.org/10.1007/ s12686-020-01149-5.

Nicole M. Phillips

N.Phillips@usm.edu

1 School of Biological, Environmental, and Earth Sciences,

The University of Southern Mississippi, Hattiesburg, MS 39406, USA

2 Charlotte Harbor Field Laboratory, Fish and Wildlife Research Institute, Florida Fish and Wildlife Conservation Commission, Port Charlotte, FL 33954, USA

3 Center for Fisheries Research and Development, The University of Southern Mississippi, Ocean Springs, MS 39564, USA 